\title{
Cytomegalovirus in urinary sediment in patients with acute kidney injury
}

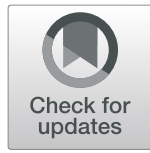

Sahra Pajenda ${ }^{1 *}$, Sebastian Kapps ${ }^{1}$, Daniela Gerges ${ }^{1}$, Gregor Hoermann ${ }^{2,3}$, Ludwig Wagner ${ }^{1}$, Nina Buchtele ${ }^{4}$, Barbara Geist ${ }^{5}$, Robert Strassl ${ }^{6}$, Alice Schmidt ${ }^{1}$ and Wolfgang Winnicki ${ }^{1}$

\begin{abstract}
Background: Immunosuppression in solid organ transplantation is associated with frequent infections. Renal allograft recipients are susceptible to opportunistic infections and can acquire human cytomegalovirus (HCMV) infections even within the allograft. There, HCMV can be found in both the glomerulus and tubular cells, but is mostly restricted to specific and circumscribed sites. Therefore, not all organ infections are identifiable by immunohistology for HCMV proteins in fine needle core biopsies. Thus, we performed a urinalysis study to search for HCMV-specific RNA transcripts in the urine sediment of patients with acute kidney injury.

Methods: Urinary sediment of 90 patients with acute kidney injury (AKI), including 48 renal transplant recipients (RTX) and 42 non-transplant recipients (nRTX), was collected from morning urine for RNA extraction and reverse transcription. The copy number of HCMV transcripts was evaluated using a UL132 HCMV-specific probe set and by real-time quantitative polymerase chain reaction (RT-qPCR).

Results: Of the 48 RTX patients, ten showed HCMV copies in their urine sediment cells. Within this group, three recipients had negative HCMV serology and received an allograft from an HCMV-seropositive donor. In addition, all three RTX patients on a belatacept-based immunosuppressive regimen had HCMV transcripts in their urine. Of the 42 nRTX patients, only two had detectable HCMV transcripts in urine sediment cells and both were under immunosuppression.

Conclusions: Ten immunosuppressed renal allograft recipients and two immunosuppressed non-transplant patients with AKI showed HCMV copies in urine sediment. Thus, HCMV positivity in urinary sediment appears to be associated with immunosuppression. This study describes a novel noninvasive method for detection of HCMV in urinary sediment. Whether all HCMV infections can be detected or only those with viral replication warrants further investigation.
\end{abstract}

Keywords: Acute kidney injury, Cytomegalovirus, Immunosuppression, Renal transplantation, Urinary sediment

\footnotetext{
* Correspondence: sahra.pajenda@meduniwien.ac.at

'Department of Internal Medicine III, Division of Nephrology and Dialysis,

Medical University of Vienna, Waehringer Guertel 18-20, 1090 Vienna, Austria

Full list of author information is available at the end of the article
}

(c) The Author(s). 2021 Open Access This article is licensed under a Creative Commons Attribution 4.0 International License, which permits use, sharing, adaptation, distribution and reproduction in any medium or format, as long as you give appropriate credit to the original author(s) and the source, provide a link to the Creative Commons licence, and indicate if changes were made. The images or other third party material in this article are included in the article's Creative Commons licence, unless indicated otherwise in a credit line to the material. If material is not included in the article's Creative Commons licence and your intended use is not permitted by statutory regulation or exceeds the permitted use, you will need to obtain permission directly from the copyright holder. To view a copy of this licence, visit http://creativecommons.org/licenses/by/4.0/ The Creative Commons Public Domain Dedication waiver (http://creativecommons.org/publicdomain/zero/1.0/) applies to the data made available in this article, unless otherwise stated in a credit line to the data. 


\section{Background}

In comparison to healthy individuals, renal transplant (RTX) recipients treated with immunosuppressive agents are more likely to develop HCMV viremia and infections. In particular, HCMV seronegative recipients (R-) from seropositive donors $(\mathrm{D}+)$ are at increased risk to develop a novel HCMV infection [1, 2]. Cell-mediated and humoral immune defense are markedly compromised in transplant recipients on immunosuppressive therapy with calcineurin inhibitors or belatacept [3, 4], among others, making the renal allograft a target for infection with epitheliotropic HCMV [5]. Of note, allograft rejection has been reportedly associated with HCMV infections [5] and leads to increased risk for deathconsorted graft failure in transplant recipients [6].

Kidney biopsy is a potent diagnostic measure in acute kidney injury (AKI) when, e.g., allograft rejection must be ruled out. However, histopathology in general is rather limited in the diagnosis of HCMV infection, although various antibodies can detect viral proteins in infected cells [7]. HCMV infection is variably distributed throughout organs and may be overlooked in biopsy specimens. Therefore, staining for early HCMV antigen is not part of the scope of conventional transplant histopathology. Quantitative titer increase of HCMV in blood does not correlate with HCMV infection in renal allografts; nevertheless, both renal tubule epithelia [8] and cells at the glomerulus [9-11] are targets of HCMV infection, leading to cellular destruction and their excretion in urine $[12,13]$.

Despite routine HCMV-specific treatment, HCMVseronegative recipients ( $\mathrm{R}-$ ) of HCMV-seropositive donors (D+) bear an independent risk for graft failure, allcause mortality and infection-related mortality, as reported in a recent study including data from the United Network for Organ Sharing/Organ Procurement and Transplantation Network [6].

In this retrospective work, we analyzed the urine sediment of transplant and non-transplant patients with acute kidney injury for HCMV transcripts. Urinary sediment was collected and total RNA was extracted, reverse transcribed and tested for the presence of HCMVUL132 transcript numbers by real-time quantitative polymerase chain reaction (RT-qPCR). Furthermore, immunofluorescence staining of urine sediment for HCMV - immediate early antigen (HCMV-IEA) was performed. The medical history of all patients was followed 24 months before the onset and 8 months after the episode of acute kidney injury.

\section{Material \& methods}

\section{Study population}

Patients undergoing AKI stages I, II or III according to the KDIGO definition [14] were consecutively enrolled from 2016 to 2020 at the Department of Medicine III, Division of Nephrology and Dialysis at the Medical University of Vienna. Inclusion criteria were an age above 18 years and the presence of acute kidney injury. The main exclusion criteria were patients with end stage renal disease receiving renal replacement therapy. Written informed consent was obtained from all study participants. The study was approved by the Ethics committee of the Medical University of Vienna (EK 1043/2016).

All methods were performed in accordance with relevant guidelines and regulations.

\section{Patient records and clinical data}

Patient data comprising demographics, comorbidities, laboratory parameters including renal function parameters and HCMV status were extracted from the medical database of the Medical University of Vienna.

\section{Urine collection and reverse transcription}

Seven $\mathrm{ml}$ of morning urine were collected and immediately centrifuged at 3500 revolutions per minute (RPM). The resultant sediment was lysed in $1000 \mu \mathrm{l}$ TriFast (Peqlab, 30-2010) and frozen at $-20{ }^{\circ} \mathrm{C}$. For isolation of total RNA the cell lysate was thawed and left for $5 \mathrm{~min}$ at room temperature. Following mixing the cell lysate with $300 \mu \mathrm{l}$ of chloroform and centrifugation for $10 \mathrm{~min}$ at $12000 \mathrm{~g}$, the RNA containing supernatant was taken off and RNA was precipitated using $250 \mu \mathrm{l}$ isopropanol. The washed RNA pellet was re-dissolved in RNase free water and subjected to reverse transcription. In brief: $400 \mathrm{ng}$ of total RNA was mixed with random primers (Invitrogen, 48190-011), dNTPs heated for $3 \mathrm{~min}$ to linearize RNA and rapidly chilled in ice water while Superscript $^{\circledast}$ III (Invitrogen, 180808-044) was added together with dithiothreitol (DTT) and reverse transcription buffer. The reaction was incubated at $25{ }^{\circ} \mathrm{C}$ for $5 \mathrm{~min}$ for primer annealing and synthesis was carried out at $52{ }^{\circ} \mathrm{C}$ for further $30 \mathrm{~min}$. The enzyme function was stopped by heating the reaction at $75^{\circ} \mathrm{C}$ for $10 \mathrm{~min}$.

\section{RT-qPCR of urinary cell CDNA and HCMV copy number determination}

An HCMV UL132 TaqMan probe (Applied Biosystems, $\mathrm{Pa} 03453400)$ was cloned into TOPO cloning vector and One Shot (Invitrogen, C4040-10) chemically competent cells were transformed with the resultant plasmid using the heat shock method. In brief: two $\mu$ l of PCR product was incubated with TOPO-vector for $5 \mathrm{~min}$ at room temperature. One $\mu \mathrm{l}$ of the plasmid was combined with $50 \mu \mathrm{l}$ One Shot E.coli and a $45 \mathrm{~s}$ heat shock was carried out in a water bath at $42{ }^{\circ} \mathrm{C}$. Cells were briefly chilled on ice and incubated for one hour at $37{ }^{\circ} \mathrm{C}$ in $250 \mu \mathrm{l} \mathrm{SOC}$ medium. Spreading of E.coli was performed on LB/Amp plates and individual clones were collected $14 \mathrm{~h}$ later. 
The UL132 encoding plasmid was isolated and has been further used as positive control and UL132 copy number determination by including a 10- fold dilution standard series in RT-qPCR experiments as follows.

One $\mu \mathrm{l}$ of urinary cell cDNA or 10-fold dilution series of UL132 encoding plasmid was mixed with $1 \mu \mathrm{l}$ of UL132-specific TaqMan probe and $5 \mu$ l universal mastermix (Applied Biosystems, 4,304,437) and diluted to a final volume of $10 \mu \mathrm{l}$, all in duplicate. The sample set up was transferred into a 96 well PCR plate and inserted into the ONEstep RT-qPCR machine which was set for recording 46 PCR cycles. For copy number evaluation the 10-fold serial dilution of a plasmid encoding the UL132 transcript was used. This reflected a spectrum of $0.5 \times 10^{2}-10 \times 10^{6}$ UL132 copies as standard curve.

\section{Cytospin preparation for urine sediment}

Seven ml urine was centrifuged at 3500 RPM for $10 \mathrm{~min}$. The resultant pellet was re-suspended in $1500 \mu \mathrm{l}$ tissue culture medium (RPM 1640 containing $10 \%$ new born calf serum). Hundred fifty $\mu \mathrm{l}$ were placed into the funnel of a cyto-centrifuge (Cytospin 3, Shandon, England). Loaded samples were spun at 1200 RPM for $4 \mathrm{~min}$. The resultant cytoslides were air dried for $2 \mathrm{~h}$ and either processed immediately or wrapped in aluminum foil and kept at $-20{ }^{\circ} \mathrm{C}$ for further use.

\section{Immunofluorescence staining}

The cytoslides were fixed in acetone for $5 \mathrm{~min}$. Subsequently, a liquid repellent barrier was drawn using an Aqua-Hold Pap Pen, where urinary cells had been deposited by the cyto-centrifuge.

The mouse monoclonal anti-human cytomegalovirus immediate early antigen (HCMV-IEA) antibody (ARGEGE, Ref 11-003, France) was diluted 1:300 in PBS (phosphate buffered saline) with blocking solution (BSA, bovine serum albumin). The rabbit antihuman AQP1 was diluted 1:800 (Millipore AB 2219). Slide incubation for the primary antibody was carried out at $4{ }^{\circ} \mathrm{C}$ in a moist chamber and the next day with Alexa Fluor 488 goat anti-rabbit (diluted 1:400) and TRIC goat anti-mouse (diluted 1:400) for $1 \mathrm{~h}$ at room temperature. Five minutes before washing $40 \mu \mathrm{l}$ of DAPI solution was added onto the slide for nuclear counterstain. After each antibody incubation, the slides were washed under constant stirring of the liquid in PBS. Finally, slides were mounted in Vectashield mounting medium for immunofluorescence (Vecotor Laboratories, Burlingham CA), covered with a coverslip and imaged with a Zeiss Axiovert confocal microscope and further processed by Adobe Photoshop version 6 .

\section{Human cytomegalovirus (HCMV) detection in plasma}

Plasma samples were analyzed for the presence of HCMV DNA at the Department of Laboratory Medicine, Division of Clinical Virology at the Medical University of Vienna. Quantitative measurement of HCMV DNA viral load by PCR was performed on an Abbott m2000 platform (Abbott Molecular, Des Plaines, Illinois, USA) using the Abbott Real-Time HCMV assay (limit of detection: 20 copies/ml).

\section{Statistical analysis}

Adherence to a Gaussian distribution was determined using the Kolmogorov-Smirnov test. Normally distributed data were described as means \pm SDs, and the independent samples Student $t$ test was utilized to compare continuous variables between the two groups (urinary HCMV transcript positive and negative). In case of a skewed distribution, data were described as medians with interquartile ranges (IQR) and were compared using the Mann-Whitney U test. Qualitative variables were described with counts and percentages and group differences were assessed using contingency tables and the Fisher's exact test. Data were analyzed with Graphpad Prism (Version 9.0 for Windows). All $P$ - values result from 2 -sided tests, with significance inferred at $P<$ 0.05 .

\section{Results}

Urine samples were collected from a total of 90 individuals during their hospitalization for acute kidney injury, obtained on the first day of admission representing the climax of disease. Out of these, 48 subjects were renal transplant recipients, 42 were non-transplant patients. Baseline characteristics of the study population are given in Table 1.

Stages of AKI were assessed by serum creatinine levels; furthermore, for all patients the underlying stage of chronic kidney disease (CKD) was reported according to current guidelines $[15,16]$. As shown in Table 1 most patients from both transplant and non-transplant groups presented with AKI stage 3 (RTX: $n=13$; nRTX: $n=35$ ). The most common causes of acute kidney injury were infection and sepsis-related $(n=24)$ and prerenal $(n=$ 14). Six patients suffered from AKI due to shock, in 9 patients AKI occurred due to a renal cause. Other reasons for AKI were postrenal $(n=4)$, toxic $(n=4)$, acute graft rejection $(n=2)$ and trauma-related $(n=1)$. Furthermore, twenty-six transplant recipients were assigned in the postoperative period of renal transplantation with no or deteriorating renal function. Among these, reasons for renal malfunction were allograft rejection $(n=9)$, thrombotic microangiopathy $(n=1)$ and tubular damage $(n=3)$. In 6 patients, histology of the graft biopsy revealed no apparent reason for delayed graft function 
Table 1 Baseline Characteristics of all Study Patients. AKI acute kidney injury, CKD chronic kidney disease, DGF delayed graft function, HCMV human cytomegalovirus, IRI ischemia reperfusion injury, n.a.not applicable, RTX renal transplantation

\begin{tabular}{|c|c|c|c|}
\hline & Study Subjects total & RTX Patients & Non-RTX Patients \\
\hline Number of subjects & 90 & 48 & 42 \\
\hline Age (years) & $58.46 \pm 15.96$ & $55.81 \pm 12.95$ & $61.48 \pm 18.37$ \\
\hline \multicolumn{4}{|l|}{ Gender - number (\%) } \\
\hline Male sex & $61(67.78)$ & $33(68.75)$ & $28(66.67)$ \\
\hline Female sex & $29(32.22)$ & $15(31.25)$ & $14(33.33)$ \\
\hline Caucasian - number (\%) & $89(98.89)$ & $48(100.00)$ & $41(97.62)$ \\
\hline Treated with immunosuppression - number (\%) & $52(57.78)$ & $48(100.00)$ & $5(11.90)$ \\
\hline \multicolumn{4}{|l|}{ Comorbidities - number (\%) } \\
\hline Hypertension & $75(83.33)$ & $42(87.50)$ & $33(78.57)$ \\
\hline Diabetes mellitus & $26(28.89)$ & $17(35.42)$ & $9(21.43)$ \\
\hline Cardiovascular disease & $27(30.00)$ & $17(35.42)$ & $10(23.81)$ \\
\hline Atrial fibrillation & $22(24.44)$ & $10(20.83)$ & $12(28.57)$ \\
\hline Cerebrovascular disease & $12(13.33)$ & $8(16.67)$ & $4(09.52)$ \\
\hline Peripheral artery disease & $13(14.44)$ & $12(25.00)$ & $1(02.38)$ \\
\hline \multicolumn{4}{|l|}{ Chronic kidney disease - number (\%) } \\
\hline CKD Stage 1 & $16(17.78)$ & $0(0.00)$ & $16(38.10)$ \\
\hline CKD Stage 2 & $10(11.11)$ & $1(02.08)$ & $9(21.43)$ \\
\hline CKD Stage 3 & $19(21.11)$ & $8(16.67)$ & $11(26.19)$ \\
\hline CKD Stage 4 & $7(07.78)$ & $5(10.42)$ & $2(04.76)$ \\
\hline CKD Stage 5 & $12(13.33)$ & $8(16.67)$ & $4(09.52)$ \\
\hline Post-transplant phase & $26(28.89)$ & $26(54.17)$ & $0(0.00)$ \\
\hline \multicolumn{4}{|l|}{ Acute kidney injury - number (\%) } \\
\hline AKI Stage 1 & $10(11.11)$ & $7(14.58)$ & $3(07.14)$ \\
\hline AKI Stage 2 & $6(06.67)$ & $2(04.17)$ & $4(09.52)$ \\
\hline AKI Stage 3 & $48(53.33)$ & $13(27.08)$ & $35(83.33)$ \\
\hline DGF/IRI & $26(28.89)$ & $26(54.17)$ & $0(0.00)$ \\
\hline HCMV detection in urinary sediment - number (\%) & $12(13.33)$ & $10(20.83)$ & $2(04.76)$ \\
\hline HCMV detection in plasma - number (\%) & $3(03.33)$ & $3(06.25)$ & $0(0.00)$ \\
\hline
\end{tabular}

(DGF), and in 7 patients, graft biopsy was not performed owing to incipient improvement of renal function or patient refusal.

The mean age of RTX patients was $55.81 \pm 12.95$ years and $61.48 \pm 18.37$ years of nRTX patients. All renal transplant patients received immunosuppressive therapy, most of them being on a calcineurin inhibitor-based $(n=43)$, belatacept-based $(n=3)$ or other regimen $(n=$ 2) (Table 2). The average cold ischemia time was $14.88 \pm 5.62 \mathrm{~h}$ and donor age was $56.00 \pm 16.45$ years.

RNA was extracted from urine sediments and immediately reverse-transcribed. The resulting CDNA was tested for UL132-RNA expression in urinary sediment using a UL132 HCMV-specific probe set and RT-qPCR. Details on transplantation and type of immunosuppression, HCMV serology status, current existing HCMV infection, history of HCMV infection as well as HCMV infection within an 8 months follow-up period of RTX patients with and without HCMV transcripts in the urinary sediment are given in Table 2 .

Ten patients of the renal transplant group tested positive for HCMV transcripts in the urinary sediment. In the non-transplant group, HCMV transcripts were detected in the urinary sediment in only two patients, both under immunosuppression (Fig. 1).

Among renal transplant patients the underlying HCMV IgG status of the donor (D) and recipient (R) at the time of transplantation did not account for the pattern of HCMV detection in urinary sediment (Table 2). Furthermore, no differences in the immunosuppressive regimen, history of induction therapy with antithymocyte globulin / immunoadsorption (ATG/ IAS) and rejection therapy between RTX patients with and without HCMV transcripts in the urinary sediment were found. 
Table 2 Clinical Characteristics and Donor-specific Data according to HCMV status in Urinary Sediment of RTX Patients. ATG antithymocyte globulin, CNI calcineurin inhibitor, DSA donor specific antibodies, D/R donor/recipient, + positive, - negative, HCMV human cytomegalovirus, IAS immunoadsorption, IQR interquartile range, n.a. not applicable, RTX renal transplantation

\begin{tabular}{|c|c|c|c|}
\hline & HCMV positive & HCMV negative & $P$-value \\
\hline Number of subjects & 10 & 38 & \\
\hline Age (years) & $56.1 \pm 13.43$ & $55.74 \pm 12.82$ & 0.938 \\
\hline \multicolumn{4}{|l|}{ Gender - number (\%) } \\
\hline Male sex & $7(70.00)$ & $26(68.42)$ & 1.000 \\
\hline Female sex & $3(30.00)$ & $12(31.58)$ & 1.000 \\
\hline \multicolumn{4}{|l|}{ Donor specific data } \\
\hline Donor Age (years) & $58.20 \pm 17.33$ & $55.44 \pm 16.14$ & 0.638 \\
\hline Cold Ischemia Time (hours) & $17.56 \pm 4.03$ & $13.28 \pm 5.68$ & 0.031 \\
\hline Deceased Donor - number (\%) & $10(100.00)$ & $32(84.21)$ & 0.320 \\
\hline Living Donor - number (\%) & $0(0.00)$ & $6(15.79)$ & 0.320 \\
\hline \multicolumn{4}{|l|}{ Immunosuppression - number (\%) } \\
\hline CNI-based Regimen & $7(70.00)$ & $36(94.74)$ & 0.054 \\
\hline Belatacept-based Regimen & $3(30.00)$ & $0(0.00)$ & 0.007 \\
\hline Other & $0(0.00)$ & $2(05.26)$ & 1.000 \\
\hline History of ATG/IAS Induction Therapy & $0(0.00)$ & $5(13.16)$ & 0.569 \\
\hline Rejection Therapy & $2(20.00)$ & $9(23.68)$ & 1.000 \\
\hline Median time (IQR) after transplantation in days & $94(51-596)$ & $17(8-76)$ & 0.019 \\
\hline \multicolumn{4}{|l|}{ Baseline DSA - number (\%) } \\
\hline positive & $0(0.00)$ & $6(15.79)$ & 0.320 \\
\hline negative & $10(100.00)$ & $32(84.21)$ & 0.320 \\
\hline \multicolumn{4}{|l|}{ Allograft rejection - number (\%) } \\
\hline yes & $2(20.00)$ & $10(26.32)$ & 1.000 \\
\hline no & $8(80.00)$ & $28(73.68)$ & 1.000 \\
\hline \multicolumn{4}{|l|}{ Baseline HCMV status - number (\%) } \\
\hline D-/R- & $0(0.00)$ & $4(10.53)$ & 0.567 \\
\hline $\mathrm{D}-/ \mathrm{R}+$ & $2(20.00)$ & $13(34.21)$ & 0.472 \\
\hline $\mathrm{D}+/ \mathrm{R}-$ & $3(30.00)$ & $5(13.16)$ & 0.336 \\
\hline $\mathrm{D}+/ \mathrm{R}+$ & $5(50.00)$ & $16(42.10)$ & 0.729 \\
\hline \multicolumn{4}{|l|}{ HCMV- specific treatment at study timepoint - number (\%) } \\
\hline yes & $3(30.00)$ & $12(31.58)$ & 1.000 \\
\hline no & $7(70.00)$ & $26(68.42)$ & 1.000 \\
\hline \multicolumn{4}{|l|}{ HCMV infection at study timepoint - number (\%) } \\
\hline yes & $1(10.00)$ & $2(05.26)$ & 0.512 \\
\hline no & $9(90.00)$ & $36(94.74)$ & 0.512 \\
\hline \multicolumn{4}{|c|}{ History of HCMV infection within the previous 2 years - number (\%) } \\
\hline yes & $2(20.00)$ & $3(07.89)$ & 0.276 \\
\hline no & $8(80.00)$ & $35(92.11)$ & 0.276 \\
\hline \multicolumn{4}{|l|}{ HCMV infection during 8-months follow up - number (\%) } \\
\hline yes & $1(10.00)$ & $6(15.79)$ & 1.000 \\
\hline no & $9(90.00)$ & $32(84.21)$ & 1.000 \\
\hline Median (IQR) of HCMV urine sediment (copies/7mL urine) & $788(552-928)$ & n.a. & \\
\hline
\end{tabular}




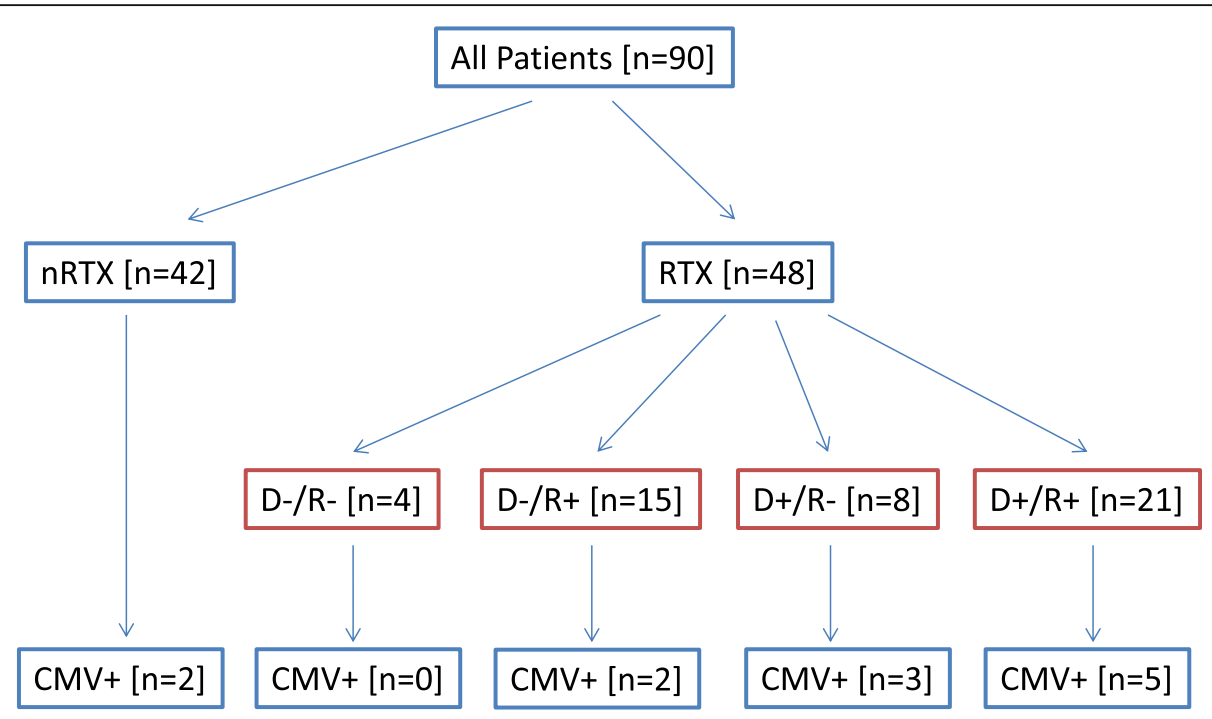

Fig. 1 Flowchart of Study Subjects. HCMV transcripts in urine sediment were positive in two of 42 non-transplant patients and in ten of 48 renal transplant recipients. HCMV+, urinary sediment positive for UL132 (HCMV-specific probe set); D/R, donor/recipient; +, positive; -, negative; nRTX, non-transplant recipient; RTX, renal transplant recipient

Of note, patients who tested positive for HCMV transcripts in urine sediment had been under immunosuppressive therapy for a longer time post transplantation compared to patients without HCMV detection (Table 2).

In patients positive for HCMV transcripts in the urinary sediment, the HCMV expression level of the cellular urine sediment, given in copy numbers, varied within a particular range (non- RTX patients: median 772 (IQR, 757-787); all RTX patients: median 788 (IQR, 552-928); D-/R+: median 404 (IQR, 221-587); D+/R-: median 952 (IQR, 750-16,938); D+/R+: median 806 (IQR, 564-857). A urine sediment sample was considered HCMV positive in this analysis with a cycle threshold below 45 cycles.

Out of the ten RTX patients positive for urinary HCMV transcripts, two patients (20\%) had an acute allograft rejection in the early phase around urinalysis, whereas ten of 38 patients $(26 \%)$ without urinary HCMV transcripts also experienced graft rejection (Table 2). In the late phase after HCMV transcript detection in urine, no further rejection episodes occurred. In addition, eight out of the ten RTX patients with positive urinary HCMV transcripts had a recovery of kidney function, two patients did not regain renal function, of which one patient died due to severe hemorrhage shock and one patient developed end-stage renal disease. Among all the 90 patients analyzed, three were positive for HCMV DNA in plasma, of which all were RTX patients under immunosuppression. In one of these three patients with high risk HCMV constellation $(\mathrm{D}+/ \mathrm{R}-)$ the urine sediment also proved positive for HCMV UL132 transcript.
To further delineate which cell types in the urinary sediment contain HCMV transcripts translated into protein, immunofluorescence staining for detecting the human cytomegalovirus immediate early antigen (HCMVIEA) was performed. This detected HCMV-IEA expression in AQP1 positive tubular epithelia cells with morphological signs of membrane damage, as shown in Fig. 2.

\section{Discussion}

The goal of this study was to investigate the presence of HCMV infected cells in urine in transplant recipients undergoing AKI. As control, non-transplant patients with AKI were included. The HCMV risk profile of all allograft recipients was assessed, as studies have previously shown that kidneys from HCMV-seropositive donors transplanted into recipients with HCMVseronegative $(\mathrm{D}+/ \mathrm{R}-)$ profiles were associated with a worse clinical outcome after transplantation [6]. The cohort of patients with AKI and positive urinary HCMV transcripts included predominantly recipients from HCMV-seropositive donors. In addition, all three patients on belatacept-based immunosuppressive regimen were positive for HCMV in urine sediment cells, which is in accordance with data of a recent study [4].

The UL132 used probe set tests for an early response gene which lies in the UL/b' region and represents a part of the UL146 gene. Although the UL132 contains some polymorphic sites [17] at the 5' end, it represents an ideal marker for the detection of most HCMV variants using this protein as target. Until now, no data were available on HCMV propagation in renal epithelial cells. Using a 

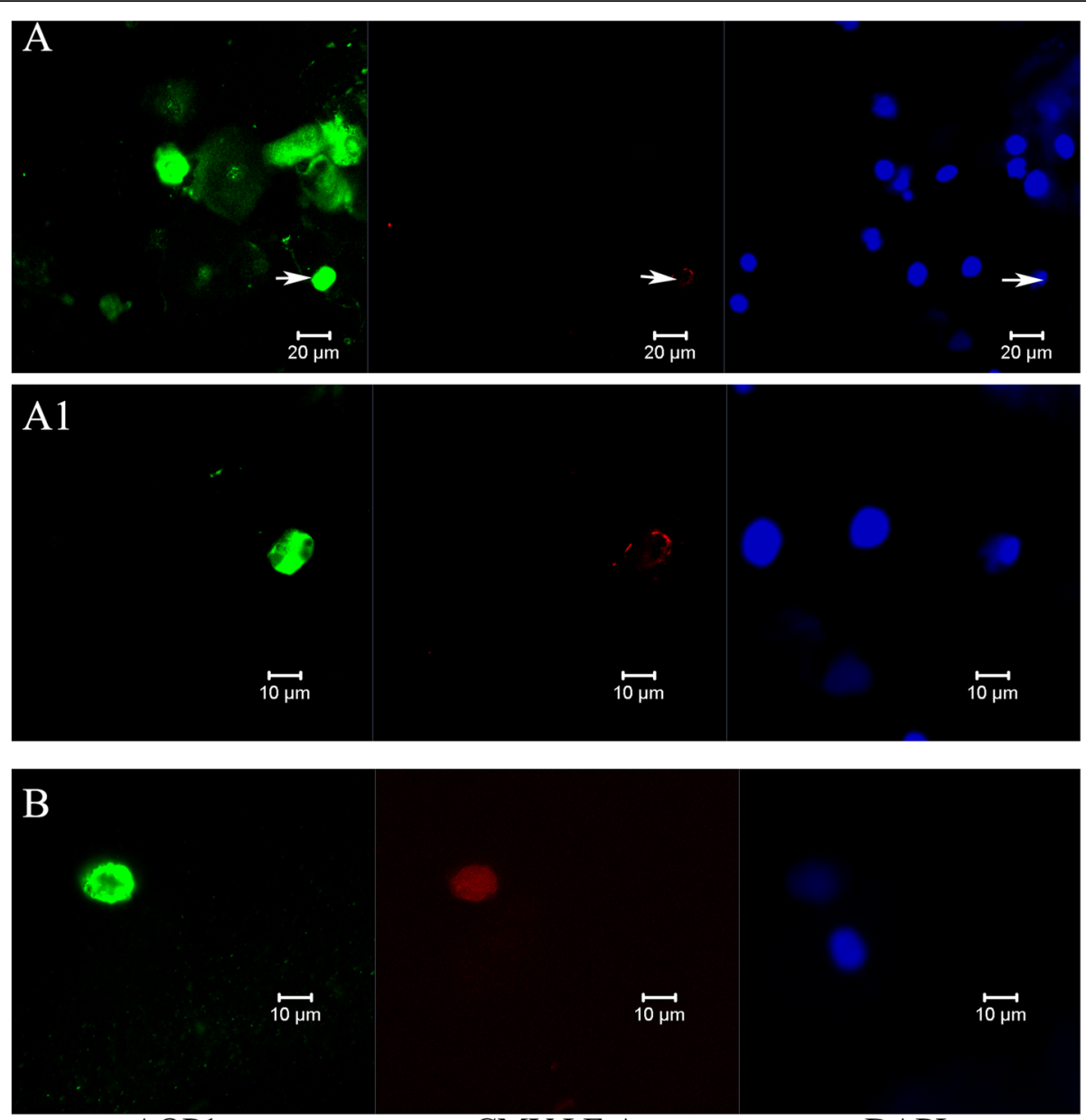

AQP1

CMV-I.E.A

DAPI

Fig. 2 Confocal immunofluorescence staining of urinary sediment for cytomegalovirus immediate early antigen (HCMV-IEA) in aquaporin 1 (AQP1) positive tubular epithelia cells with different distribution pattern. Staining for HCMV-IEA is shown in red, for AQP1 in green and for DAPI in blue. A: marginal staining of HCMV-IEA at the nuclear edge. The cell marked with an arrow $(\rightarrow)$ is shown at higher magnification in A1. B: HCMVIEA staining of the nucleus

Taqman UL132 specific probe and urinary sediment cDNA from 90 patients undergoing AKI, the presence of HCMV transcripts could be analyzed in urinary sediment cells. Positive reactions were found in ten patients out of 48 renal transplants recipients. Of note, two patients with deteriorating renal function immediately after renal transplantation from a HCMV-seropositive organ donor initially had a HCMV-positive urine sediment that disappeared when renal function improved. This is consistent with recent data that reperfusion injury itself can reactivate latent infections [18]. In addition, immunofluorescence staining for HCMV-IEA of urine sediment in RTX patients with urinary HCMV transcripts showed positive expression in tubular epithelial cells with morphological features of membrane damage.

Of note, two non-transplant patients who were on immunosuppressive therapy also tested positive for HCMV copies in the urine sediment analysis.
Although it has been shown that HCMV infections cause cellular and humoral immune responses such as antibody production [19] and T-cell immunity [20], some of the HCMV-specific antibodies are neutralizing. It is therefore conceivable that the immune system may keep the infection at a low rate of spread. Following recovery from the disease, replication of the pathogenic virus is most likely suppressed and placed into a latent status.

Our observation of HCMV detection after transplantation in the urine sediment is in accordance with findings in animal experiments. Reactivation of latent HCMV was recently described in a murine model facilitated by implantation of a latently infected allogeneic kidney together with administration of immunosuppression. HCMV was reactivated within the allogeneic kidney and also spread to other organs [18]. 
This study cannot answer the question whether RTqPCR of urine sediment cells can detect HCMV infection with renal involvement in all cases. However, the study clearly shows that immunosuppression in general and immunosuppressive therapy regimens in particular predispose to HCMV detection in urinary sediment. This is consistent with studies showing that the type of immunosuppression has a significant impact on replication of latent viruses [21]. The major limitation of the present work is the retrospective design. In addition, no follow-up urine samples were systematically collected. The HCMV DNA in plasma was detected in only a few patients and was not measured in urine as the focus was on determining the HCMV transcript UL132 in urinary cell sediment by reverse transcription of urinary cellderived RNA. Furthermore, histologic reports from renal biopsies were not available for the entire study cohort. On the other hand, our study was strengthened by a substantial sample size and a well-characterized patient cohort consisting of immunosuppressed and nonimmunosuppressed patients with acute kidney injury.

\section{Conclusions}

This study describes a novel method for detecting HCMV infections in renal allograft patients using a noninvasive test in urine sediment. However, two nontransplant patients under immunosuppression due to an underlying disease also tested positive for HCMV. Hence, positive urinary sediment for HCMV transcripts is accompanied with immunosuppression. It does not, however, allow conclusions whether all HCMV infections can be detected or only those with viral replication.

\footnotetext{
Abbreviations

AKI: Acute kidney injury; ATG: Antithymocyte globulin; CKD: Chronic kidney disease; D: Donor lgG status of HCMV; DGF: Delayed graft function; DNA: Deoxyribonucleic acid; dNTP: Deoxyribonucleotide triphosphate; DTT: Dithiothreitol; HCMV: Human cytomegalovirus; HCMV-IEA: HCMV immediate early antigen; IAS: Immunoadsorption; IQR: Interquartile range; IRI: Ischemia reperfusion injury; nRTX: Non-transplant recipient; PBS: Phosphate buffered saline; R: Recipient IgG status of HCMV; RNA: Ribonucleic acid; RTX: Renal transplant recipient; RPM: Revolutions per minute; RT-qPCR : Real-time quantitative polymerase chain reaction
}

\section{Acknowledgements}

Not applicable.

\section{Authors' contributions}

S.P., L.W. and W.W. conceived and designed the experiments and wrote the main manuscript text. S.P., S.K., D.G., G.H., L.W., N.B. and R.S. performed the experiments. S.P., B.G. and A.S. analyzed the data. L.W. and W.W. contributed reagents/materials/analysis/tools. All authors reviewed drafts of the paper and approved the final manuscript.

\section{Funding}

No funding was obtained for this study.

\section{Availability of data and materials}

Data supporting the findings of this study are available upon request from the corresponding author.

\section{Declarations}

Ethics approval and consent to participate

This study was approved by the Ethics committee of the Medical University of Vienna (EK 1043/2016). Written informed consent was obtained from all study participants.

\section{Consent for publication \\ Not applicable.}

\section{Competing interests}

The authors declare that they have no competing interests.

\section{Author details}

'Department of Internal Medicine III, Division of Nephrology and Dialysis, Medical University of Vienna, Waehringer Guertel 18-20, 1090 Vienna, Austria. ${ }^{2}$ Department of Laboratory Medicine, Medical University of Vienna, Vienna, Austria. ${ }^{3}$ MLL Munich Leukemia Laboratory, Munich, Germany. ${ }^{4}$ Department of Internal Medicine I, Stem Cell Transplantation Unit, Medical University of Vienna, Vienna, Austria. ${ }^{5}$ Department of Biomedical Imaging and ImageGuided Therapy, Division of Nuclear Medicine, Medical University of Vienna, Vienna, Austria. ${ }^{6}$ Department of Laboratory Medicine, Division of Clinical Virology, Medical University of Vienna, Vienna, Austria.

Received: 28 January 2021 Accepted: 20 April 2021

Published online: 08 May 2021

\section{References}

1. Hartmann A, Sagedal S, Hjelmesæth J. The Natural Course of Cytomegalovirus Infection and Disease in Renal Transplant Recipients. Transplantation. 2006;82(2 Suppl):S15-7.

2. Helantera I, Kyllonen L, Lautenschlager I, Salmela K, Koskinen P. Primary CMV infections are common in kidney transplant recipients after 6 months valganciclovir prophylaxis. Am J Transplant. 2010;10(9):2026-32.

3. Egli A, Kumar D, Broscheit C, O'Shea D, Humar A. Comparison of the effect of standard and novel immunosuppressive drugs on CMV-specific T-cell cytokine profiling. Transplantation. 2013;95(3):448-55.

4. Karadkhele G, Hogan J, Magua W, Zhang W, Badell IR, Mehta A, et al. CMV high-risk status and posttransplant outcomes in kidney transplant recipients treated with belatacept. Am J Transplant. 2021;21(1):208-21.

5. Vichot AA, Formica RN, Jr., Moeckel GW. Cytomegalovirus glomerulopathy and cytomegalovirus interstitial nephritis on sequential transplant kidney biopsies. Am J Kidney Dis. 2014;63(3):536-9.

6. Leeaphorn N, Garg N, Thamcharoen N, Khankin EV, Cardarelli F, Pavlakis M. Cytomegalovirus mismatch still negatively affects patient and graft survival in the era of routine prophylactic and preemptive therapy: A paired kidney analysis. Am J Transplant. 2019;19(2):573-84.

7. Chemaly RF, Yen-Lieberman B, Castilla EA, Reilly A, Arrigain S, Farver C, et al. Correlation between viral loads of cytomegalovirus in blood and bronchoalveolar lavage specimens from lung transplant recipients determined by histology and immunohistochemistry. J Clin Microbiol. 2004; 42(5):2168-72.

8. Krogerus L, Soots A, Loginov R, Bruggeman C, Lautenschlager I. CMV increases tubular apoptosis through the TNF-alpha-TNF-R1 pathway in a rat model of chronic renal allograft rejection. Transpl Immunol. 2008; 18(3):232-6.

9. Spencer ES, Jepsen FL. Glomerulopathy in renal allografts from patients with and without active Cytomegalovirus infection. Dan Med Bull. 1989;36(3): 300-1.

10. Suneja M, Nair R. Cytomegalovirus glomerulopathy in a kidney allograft with response to oral valganciclovir. Am J Kidney Dis. 2008:52(1):e1-4.

11. Luo X, Rajagopal A, Ison M, Friedewald J, Leventhal J, Kanwar Y. Two rare forms of renal allograft glomerulopathy during cytomegalovirus infection and treatment. Am J Kidney Dis. 2008;51(6):1047-51.

12. Gerstenkorn C, Robertson H, Mohamed MA, O'Donnell M, Ali S, Talbot D. Detection of cytomegalovirus (CMV) antigens in kidney biopsies and transplant nephrectomies as a marker for renal graft dysfunction. Clin Chem Lab Med. 2000;38(11):1201-3.

13. Rowshani AT, Bemelman FJ, van Leeuwen EM, van Lier RA, ten Berge IJ. Clinical and immunologic aspects of cytomegalovirus infection in solid organ transplant recipients. Transplantation. 2005;79(4):381-6. 
14. Kellum JA, Lameire N, Group KAGW. Diagnosis, evaluation, and management of acute kidney injury: a KDIGO summary (Part 1). Crit Care. 2013;17(1):204.

15. Inker LA, Astor BC, Fox CH, Isakova T, Lash JP, Peralta CA, et al. KDOQI US Commentary on the 2012 KDIGO Clinical Practice Guideline for the Evaluation and Management of CKD. Am J Kidney Dis. 2014;63(5):713-35.

16. Khwaja A. KDIGO Clinical Practice Guidelines for Acute Kidney Injury. Nephron Clin Pract. 2012;120(4):C179-C84.

17. Sun ZR, Ji YH, Ruan Q, He R, Ma YP, Qi Y, et al. Genetic variability of human cytomegalovirus UL132 gene in strains from infected infants. Microbiol Immunol. 2006;50(10):773-9.

18. Zhang Z, Qiu L, Yan S, Wang JJ, Thomas PM, Kandpal M, et al. A clinically relevant murine model unmasks a "two-hit" mechanism for reactivation and dissemination of cytomegalovirus after kidney transplant. Am J Transplant. 2019;19(9):2421-33.

19. Wang Z, La Rosa C, Maas R, Ly H, Brewer J, Mekhoubad S, et al. Recombinant modified vaccinia virus Ankara expressing a soluble form of glycoprotein B causes durable immunity and neutralizing antibodies against multiple strains of human cytomegalovirus. J Virol. 2004;78(8):3965-76.

20. van Leeuwen EM, Remmerswaal EB, Vossen MT, Rowshani AT, Wertheim-van Dillen PM, van Lier RA, et al. Emergence of a CD4 + CD28- granzyme B+, cytomegalovirus-specific $\mathrm{T}$ cell subset after recovery of primary cytomegalovirus infection. J Immunol. 2004;173(3):1834-41.

21. Haidar G, Singh N. Viral infections in solid organ transplant recipients: novel updates and a review of the classics. Curr Opin Infect Dis. 2017;30(6):579-88.

\section{Publisher's Note}

Springer Nature remains neutral with regard to jurisdictional claims in published maps and institutional affiliations.

Ready to submit your research? Choose BMC and benefit from:

- fast, convenient online submission

- thorough peer review by experienced researchers in your field

- rapid publication on acceptance

- support for research data, including large and complex data types

- gold Open Access which fosters wider collaboration and increased citations

- maximum visibility for your research: over $100 \mathrm{M}$ website views per year

At BMC, research is always in progress.

Learn more biomedcentral.com/submissions 